\title{
How Much Do Americans Like Jews?: Approaches to Social Attitude Measurement
}

Sid Groeneman ${ }^{*}$

Tags: survey practice

\section{Survey Practice}

Vol. 1, Issue 3, 2008

How Much Do Americans Like Jews?: Approaches to Social Attitude Measurement

How others regard Jews has been the focus of considerable social science research, typically conceptualizing Jews as a cultural out-group, and often motivated by a concern with anti-Semitism. The emphasis has been on measuring ethno-centrism and negative attitudes. This research maintains that reliance on direct affect measurement tools results in more comprehensive, more affirmative, and less misleading assessments than evaluations based on stereotypes or social distance measures.

\section{APPROACHES TO MEASURING SOCIAL ATTITUDES}

Attitudinal research about Jews (and other minority groups) has relied primarily on three types of measures. "Social distance" measures include questions about comfort level in interactions: living in a neighborhood with Jewish residents, working with Jewish co-workers or superiors, having a close relative marry a Jew, and so forth. Negative responses to these kinds of questions have been used as indicators of dislike.

For example, the National Opinion Research Center's 2000 General Social Survey found that $9 \%$ of Americans objected to living in a neighborhood "where half of your neighbors were Jews"; and 13\% were opposed to having "a close relative marry a Jewish person”. A 2006 Gallup/USA Today Poll found that $5 \%$ would not like to have Jews as neighbors. Such results are taken as uniformly negative feelings. However, even these modest proportions might not be expressing negativity. The problem is that desire to avoid closeness might represent a preference to be with members of one's own ethnic, religious, or racial group (or fear of assimilation), and not antipathy.

Similar considerations about misleading or exaggerated interpretation also apply to the second method, measurement of stereotypes. Agreement with stereotypic statements about Jewish "control" of Wall Street or the media, or of negative Jewish personality traits, have been used as indicators of hostility. 
Like the social distance approach, ascertaining the prevalence of stereotyping has a storied tradition in social research. Some of the measures used - for example, Jews being avaricious or scheming - denote indisputably negative perceptions. Other stereotypes, such as disproportionate Jewish influence in the entertainment industry, or Jewish wealth, convey more ambiguous meanings.

In some cases, erroneous inferences can result from an absence of context: A 1996 Pew Research Center survey found 49\% preferring that Jews have less political power - which, in isolation, would be a strong negative indictment. However, the same survey also found the public preferring that Catholics (53\%), Evangelicals (51\%), and even Protestants (44\%) have less power. Jews were hardly the only target of this perception.

Even the oft discussed notion that Jews were responsible for the crucifixion of Christ does not always indicate negativity. During the height of interest in Mel Gibson's controversial 2004 film The Passion of the Christ, 26\% responded in a Pew Research Center survey that Jews were responsible for Christ's death. Some took this as disturbing evidence of contemporary anti-Semitism. But, when $\mathrm{ABC}$ News asked respondents if they agree or disagree that "All Jews today bear responsibility for the death of Jesus," only $8 \%$ agreed - a sharply lower figure.

Despite disagreement over meaning and exaggeration of its significance in some instances, stereotypes of Jews are still quite prevalent, some of them held by upwards of $25-30 \%$ or more of U.S. adults. ${ }^{1}$ That said, it is also necessary to recognize that a person can hold a negative stereotype of a group while simultaneously having overall positive feelings toward that group.

The foregoing is not to argue against all measurement of stereotypes or social distance - only that these approaches have sometimes produced exaggerated estimates and overblown conclusions about the degree of implied negativity.

The third type of attitude research relies on purer affect measures - those which most directly gauge both positive and negative feelings. This type of measure comes in a variety of flavors, but the most common asks about favorability of opinion, as in the Pew Research Center series of surveys: 
Table 1 Favorability Toward Jews (Pew Research Center).

$\begin{array}{llll} & \text { \% Very/Mostly } & \text { \% Very/Mostly } & \text { \% Don't Know/ } \\ & \text { Favorable } & \text { Unfavorable } & \text { Can't rate/Other } \\ \text { Spring 2008 } & 77 & 7 & 17 \\ \text { March 2007 } & 69 & 10 & 21 \\ \text { Spring 2006 } & 77 & 5 & 17 \\ \text { May 2005 } & 76 & 7 & 16 \\ \text { March 2004 } & 77 & 8 & 15 \\ \text { June 2003 } & 72 & 9 & 19 \\ \text { February 2002 } & 74 & 9 & 17 \\ \text { March 2001 } & 72 & 10 & 18 \\ \text { August 2000 } & 77 & 8 & 15 \\ \text { June, } 1997 & 82 & 9 & 9\end{array}$

The level of unfavorable opinion toward Jews over the past decade ranges quite narrowly between 5-10\%, and with no apparent trend. The fairly high proportion of "Don't know/other" responses is ambiguous. It probably signifies a combination of things: unfamiliarity with Jews, ${ }^{2}$ unwillingness to generalize, a desire to answer neither/neutral/in-between, and, in some cases, an unwillingness to admit unfavorable views. A 2000 ABC News/Washington Post poll tried to address the latter possibility directly: "If you honestly assessed yourself, would you say that you have some negative feeling about Jews?" Those results ( $4 \%$ yes, $95 \%$ no, $1 \%$ no opinion) found few admitting a reluctance to disclose negativity.

Exhibit 1 displays results from a Gallup Poll taken this past Spring, which asked how positive or negative people feel about "...different religious or spiritual groups in the United States". This question offered an explicit "Neutral" response option. Compared to others, Jews are viewed quite favorably, with net positive scores only narrowly behind Methodists, slightly higher than Catholics and Baptists, and substantially ahead of six other groups. 


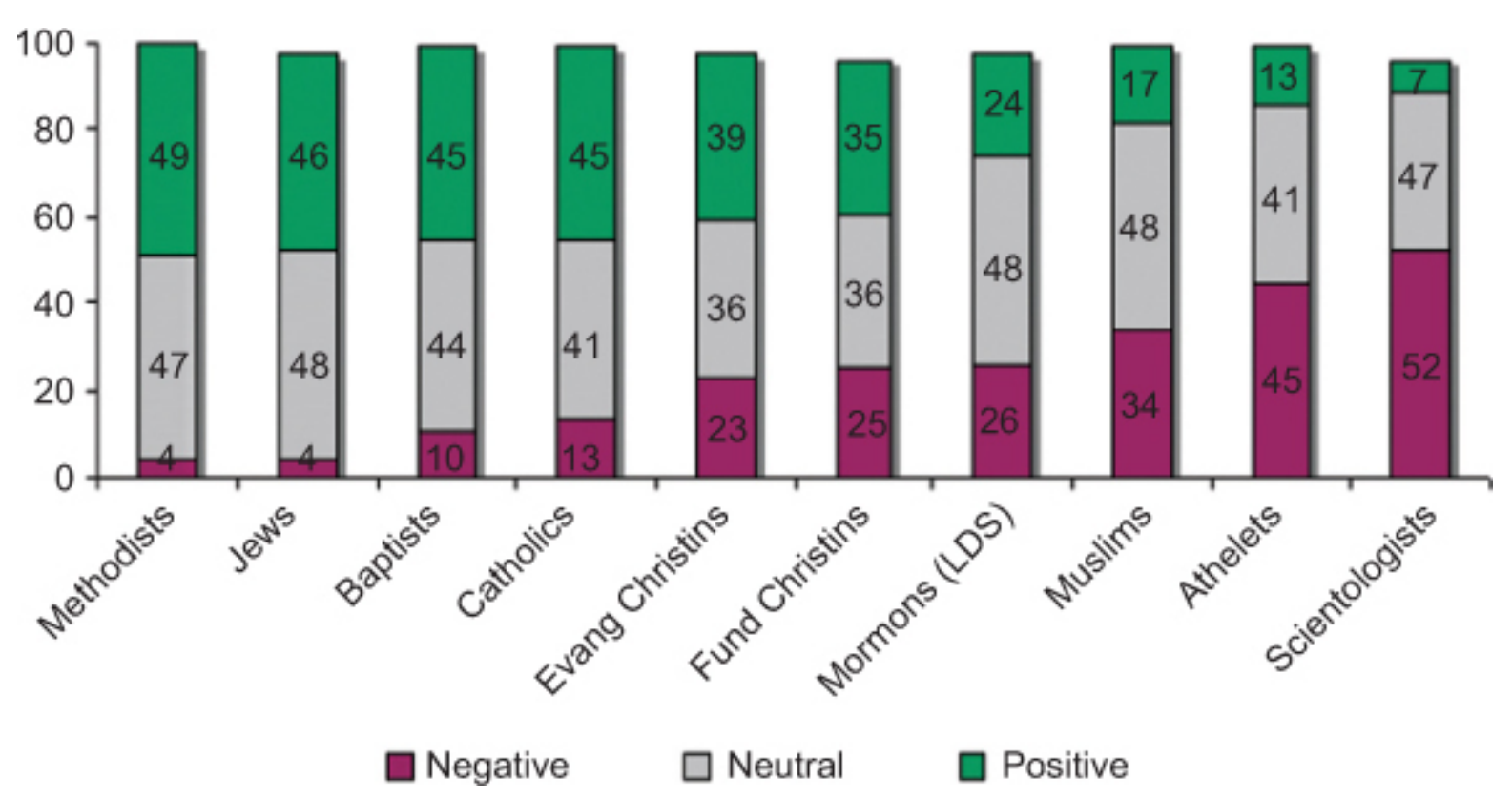

Exhibit 1 Views of Religious and Spritual Groups (Gallup - March, 2008).

Another type of direct affect measure, the "feeling thermometer," has been widely applied in measuring attitudes of public figures and political/ethnic/ religious groups. It ranges in one-degree increments from $0^{\circ}$ (Very Cold or Unfavorable Feeling) to $100^{\circ}$ (Very Warm or Favorable Feeling). With a greater number of discrete scale points than other measures, the feeling thermometer has the ability to capture finer gradations of sentiment. Like Gallup's measure but unlike Pew's, it has an explicit middle point at the $50^{\circ}$ mark (labeled "No Feeling At All"), facilitating a valid reply from respondents perceiving the group neither favorably nor unfavorably.

Exhibit 2 shows the latest feeling thermometer ratings of Jews:

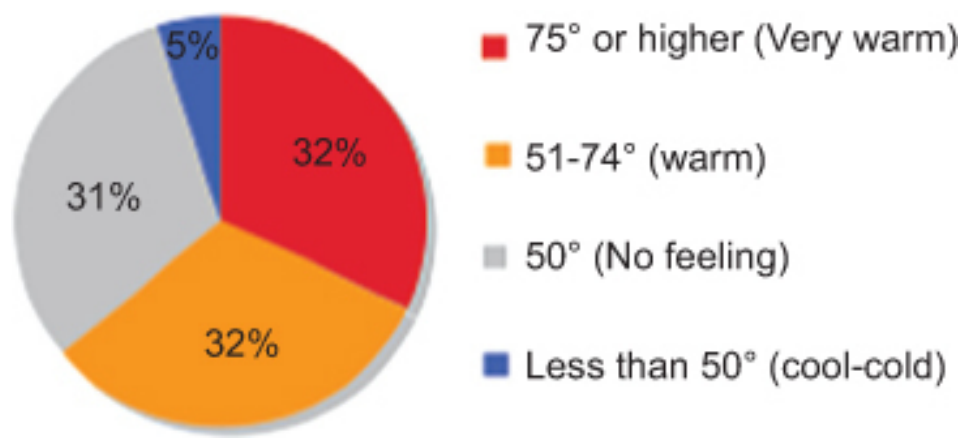

Exhibit 2 Americans' Feelings Toward Jews (ANES 2004) (Jewish respondents excluded).

These ratings too suggest that Americans feel quite favorable toward Jews: Over half $(64 \%)$ hold warm feelings $\left(>50^{\circ}\right)$ toward Jews, with half of those attitudes above $50^{\circ}$ - or nearly one-third of the total - being quite favorable, at $75^{\circ}$ or warmer. Another $31 \%$ gave ratings of $50^{\circ}$ (no feeling). Only $5 \%$ chose 
cool-to-cold scores (less than $\left.50^{\circ}\right){ }^{3}$

\section{APPLYING THE FEELING THERMOMETER TO OTHER GROUPS}

Exhibit 1 suggested that Jews are viewed positively compared to other religious groupings. Does this conclusion hold when temperature thermometer comparisons are made with other groups in American society? Since Jews are also an ethnic or cultural group — not only adherents of a distinctive religion - it is appropriate to examine how they are viewed among a broader set of social groupings (Exhibit 3).

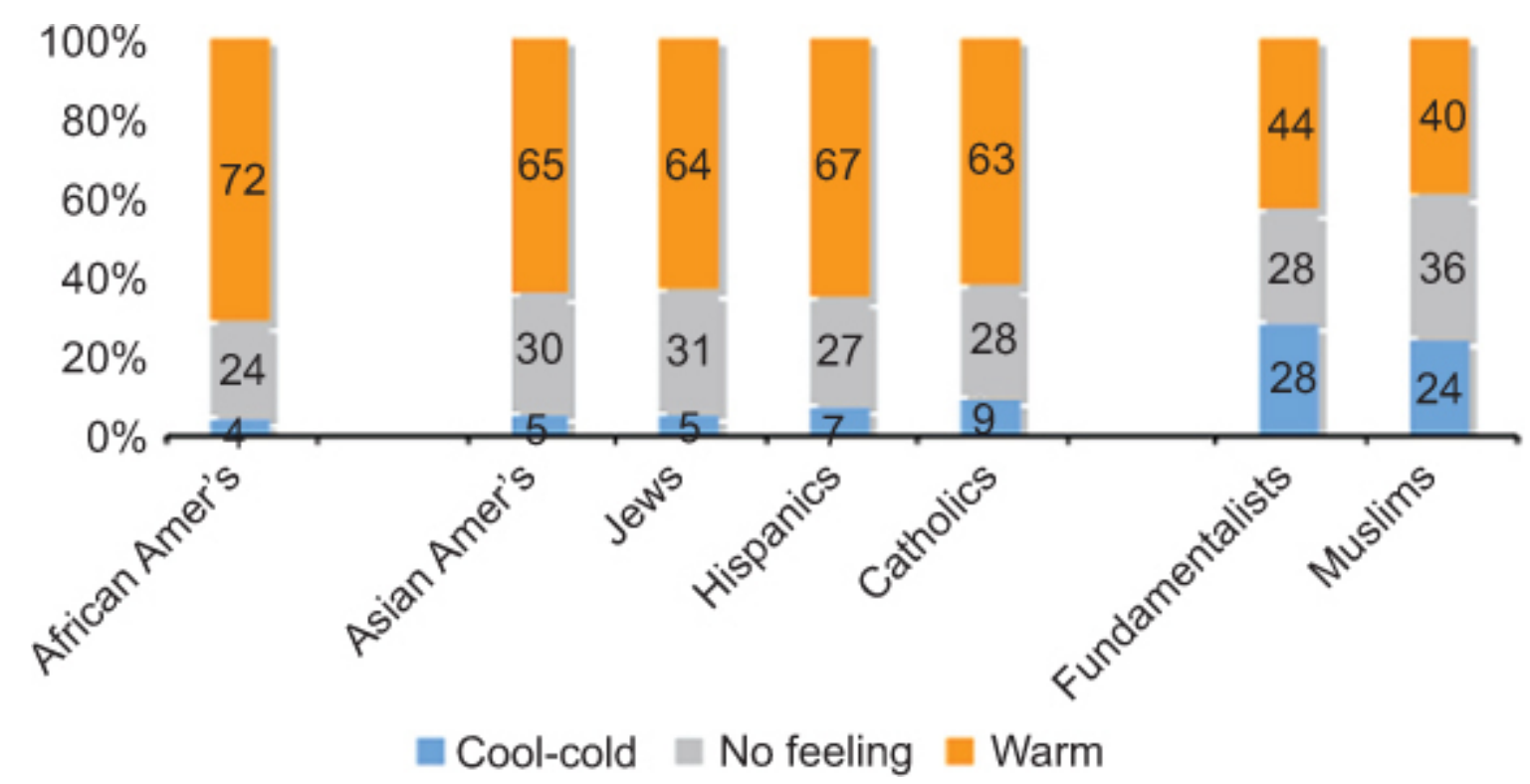

Exhibit 3 Feeling Thermometer Ratings of Various Groups (American National Election Studies survey 2004) (Respondents in group excluded from group's ratings).

Among the seven groups rated in the ANES survey, Americans feel as warmly toward Jews as toward Catholics, Hispanics, and Asian Americans - and considerably more so than toward Christian Fundamentalists and Muslims. African Americans receive warmer ratings. ${ }^{4}$ These data present a moderating counterpoint to the more strongly favorable image of Jews suggested by the previous data: While Jews are warmly regarded by most Americans, so are other ethnic minorities.

African Americans' higher thermometer score is unexpected. Except perhaps for Muslims - who constitute a small fraction of the U.S. population ${ }^{5}$ but

\footnotetext{
3 There are moderate subgroup differences by age and education. Those with more formal education rate Jews more warmly (based on mean thermometer response): < HS grad: 60.1Õ, HS grad: 65.9Õ, Some college: 68.6Õ, College graduates: 69.6Õ. So do older compared to younger respondents: $18-34$ (63.2Õ), 35-54(65.8Õ), 55+ (71.20̃).

4 The mean thermometer scores are: African-Americans $-69.5^{\circ}$, Asian-Americans $-67.2^{\circ}$, Jews $-66.7^{\circ}$, Hispanics $-66.5^{\circ}$, Catholics $-66.0^{\circ}$, Fundamentalists $-54.2^{\circ}$, Muslims $-53.6^{\circ}$.

5 In 2002, Tom W. Smith, Director of the GSS, calculated a best estimate of the U.S. Muslim population to be $0.67 \%$ ( 1.9 million people) - and possibly as many as $1.0 \%$ of the population ( 2.8 million) if "high-side" estimates based on local surveys, figures from mosques, and ancestry
} 
suffer a special burden in our highly charged post-911 atmosphere - African Americans likely encounter greater prejudice and discrimination than other groups. So, it is puzzling that they are the recipients of the most positive ratings. Might the expressed attitudes reflect compensatory sentiment?, a genuine response to the sustained teaching of the immorality of racial prejudice?, or possibly a reflection of greater reluctance to admit one's true feelings toward African Americans?

\section{CONCLUDING THOUGHTS}

Americans like Jews at least as much as other religious and ethnic/racial groups in American life, with the possible exception of African Americans. Although other research documents that certain stereotypes about Jews remain prevalent and that small proportions of adults prefer to maintain some social distance, overall attitudes are quite favorable.

This research expresses a preference for direct affect measurement over exclusive reliance on stereotypes and social distance because it results in more accurate attitude assessments. A few questions beg further investigation. First, how many of the "neutrals" and "don't know" responses are hiding negative feelings, and what do the answers of the rest signify - unfamiliarity?, unwillingness to compare social groups? Some form of research less intrusive than interviews might begin to answer the first question. In-depth follow-up probing might help us understand the second. As a corollary question: To the extent that some are disguising their antithetical views, is this manifested equally across different social groups, or are Americans less inclined to divulge their true feelings about some (African Americans?) than others? - an issue much on the minds of pollsters and poll watchers this election season. 